\title{
Democratic Theory and the Empirical Study of Popular Vote Processes
}

Altman, David. 2018. Citizenship and Contemporary Direct Democracy.

Cambridge: Cambridge University Press.

Dyck, Joshua, and Edward Lascher. 2019. Initiatives without Engagement:

A Realistic Appraisal of Direct Democracy's Secondary Effects. Ann Arbor,

MI: University of Michigan Press.

Hollander, Saskia. 2019. The Politics of Referendum Use in European

Democracies. London: Palgrave MacMillan.

Matsusaka, John G. 2020. Let the People Rule: How Direct Democracy Can

Meet the Populist Challenge. Princeton, NJ: Princeton University Press.

\section{Spencer McKay}

The institutionalization and use of popular vote processes, ${ }^{1}$ such as referendums and initiatives, has grown substantially since the 1970s (Altman 2011). The growth in the number and significance of popular vote processes has coincided with a surge in scholarly attention. By reviewing four recent books on popular vote processes, I illustrate how the authors arrive at distinct normative judgments regarding the democratic value of popular vote processes and try to illustrate the need for a normative theory of these processes that accounts for a wide variety of institutional designs and political contexts.

The four books under review arrive at different conclusions about the relationship between popular vote processes and democracy. John Matsusaka's Let the People Rule: How Direct Democracy Can Meet the Populist Challenge is the most optimistic, drawing largely on the use of referendums and initiatives in US states. He contends that American democracy has become unresponsive to citizens and that "we should fix the problem by making government more democratic," namely by developing a national initiative process $(\mathrm{x})$.

Joshua Dyck and Edward Lascher's Initiatives Without Engagement: A Realistic Appraisal of Direct Democracy's Secondary Effects studies the Californian experience and suggests that initiatives need to be approached with 
caution. Contrary to the expectations of participatory democrats, they find that popular initiatives do not produce more informed and engaged citizens. Popular initiatives, as used in California, might actually diminish citizens' trust in elected representatives.

The Politics of Referendum Use in European Democracies, by Saskia Hollander, shows that the adoption of popular vote processes across Europe is motivated largely by strategic considerations of political elites, rather than by a concern for democratization. As a result, the design of referendums is more likely to reflect than disrupt the existing party system.

Lastly, in Citizenship and Contemporary Direct Democracy, David Altman argues that citizen-initiated popular vote processes are generally adopted in times of political instability and that, although they are increasingly used by extremists who oppose the current government, they offer greater potential for democratization than other democratic innovations.

The four books adopt different data and methods, although they largely share a conceptual approach. At one end of the spectrum, Hollander uses case studies to develop a "thick description" of referendum politics in six European Union countries. ${ }^{2}$ At the other end, Altman argues that it is time to move "beyond the safe, traditional, case-based approach to direct democracy and jump into the murky waters of 'big' comparative politics" (19), drawing on original datasets that document the adoption and use of popular vote processes around the world over the last century. Matsusaka and Dyck and Lascher land somewhere in the middle, focusing primarily on survey data from American election studies. Despite differences in geographic scope, methodology, and substantive focus, all of these books share a systemic orientation toward the study of popular vote processes that is marked by attention to institutional variation and consideration of the interplay between referendums and the broader political system (Hug 2009).

Democratic theorists also increasingly examine popular vote processes as institutions within democratic systems (el-Wakil and McKay 2019; Jäske and Setälä 2019; Parkinson 2020). This reflects a commitment to facilitating a different set of lenses than that provided by models of direct or representative democracy and permits theorists to learn from emerging practice (Saward 2019; Warren 2017). It also emphasizes democratic theory as a process of problem-solving that aims to "develop normative guidelines for democratic societies in close interaction and collaboration with empirical research" (Fleuß and Schaal 2019: 13; see also el-Wakil and McKay 2020).

The essay proceeds as follows. First, I summarize the conceptual approach and highlight its affinity with systemic democratic theory. Second, I examine responsiveness as a key criterion for evaluating popular 
vote processes, and suggest that it devalues practices of representation. Third, I suggest that the democratic quality of popular votes cannot be grounded in participatory democratic theory. Fourth, I suggest that empirical evidence that points to the strategic adoption and use of popular vote processes does not require giving up on their democratic potential. Lastly, I review attempts to measure the democratic quality of referendums and suggest that democratic theorists need to improve the underlying concept.

\section{Popular Vote Processes as Institutions}

Situating popular vote processes within the broader political context requires a sufficient understanding of how different institutional designs change incentives for political actors. Unfortunately, as Hollander points out, the "bulk of referendum literature, variations in referendum types and the associated provisions within and across countries are often disregarded" (264). ${ }^{3}$ Even though Altman continues to use the umbrella term "mechanisms of direct democracy," which can lead to overgeneralization or insufficient attention to institutional difference (el-Wakil and McKay 2019), he acknowledges that "direct democracy has different meanings in different places, and the different institutional components of this concept (popular initiatives, referendums, or plebiscites) have diverse normative undertones" (6).

It is to their credit then, that these four books are generally careful to specify the particular institutions that they are discussing while acknowledging that they share some key features. Altman, Hollander, and Matsusaka all present typologies that are largely consistent with previous classifications. They agree on the need to distinguish between whether a popular vote process is triggered by citizens or their representatives ("bottom-up" or "top-down" in Altman's terminology), and acknowledge the existence of constitutionally mandatory referendums. Dyck and Lascher, by contrast, focus almost solely on the popular initiative, which they define as "an institution whereby citizens of a state or locality can write and qualify laws for a popular vote by collecting petition signatures from fellow citizens. If a sufficient number of signatures are collected, the measure goes on the ballot" (5).

Some of the books are better placed to discuss the implications of institutional variation than others. While Dyck and Lascher make several brief references to the existence of a "veto referendum" $(26,46)$ and the indirect initiative $(28,159)$ in some states, their analyses do not 
investigate the potential significance of this variation. Similarly, Hollander's case studies do not include any country that has provisions for citizen-initiated popular vote processes. Italy appears to have been rejected as a possible case because it is exceptional in this respect, and Hollander acknowledges that this limits the scope of many of the findings to the effects of "top-down" popular vote processes initiated by the executive or legislative branches (17).

Failure to attend to institutional variation can lead to normative conclusions that rely on the selective use of evidence and overgeneralization. Matsusaka warns that "[c]ritics often cherry-pick the rich history of direct democracy, neglecting the broader picture of its successful operation in the United States and across the globe for a century or more" (x). Altman similarly points out that there are so many kinds of popular vote processes "that have produced so many different results, it is always possible to find an example in support of whatever narrow argument one wants to make" (20). Indeed, the authors warn that the United Kingdom's Brexit referendum and California's Proposition 13 are often presented as clear examples of the failure of popular vote processes (Altman: 42; Hollander: 196; Matsusaka: 152-53).

The problem of overgeneralization appears to be partly a consequence of the pervasive language of "direct democracy" that obscures different institutional effects. Matsusaka defines "direct democracy" as "any form of democracy in which the people vote on policies, rather than voting on candidates who themselves choose the policies" (62). Such an approach is common (Altman: 7), although it can allow for overgeneralization, such as when Dyck and Lascher suggest that "some studies found that direct democracy encouraged voting, political efficacy, political knowledge, interest in politics, and other indicators of civic involvement" (153, emphasis added). While Dyck and Lascher are using the language of "direct democracy" that is common in earlier studies, their summary is based almost entirely on research into initiatives in US states and may not generalize to government-initiated referendums, mandatory referendums, and other citizen-initiated referendums (e.g., the Swiss facultative referendum).

Altman notes that direct democracy is a "polysemic concept" with a wide variety of possible meanings (6), and it is partially for this reason that there have been calls to do away with the concept altogether to emphasize that popular vote processes have different democratic costs and benefits, depending on their design and integration with other institutions (el-Wakil and McKay 2019). In the following sections, I explore some of the costs and benefits of popular vote processes in relation to democratic ideals of responsiveness, citizenship, and institutional design. 


\section{Responsiveness and Representation}

The first section of Matsusaka's book outlines the ways in which the administrative state, courts, and unresponsive legislators have reduced the capacity for a majority of citizens to see their stated policy preferences implemented. He emphasizes that citizens "feel they have lost control of the government" (3), and sees popular vote processes as providing a tool of majoritarian policymaking. While some minimal amount of responsiveness is necessary (Sabl 2015), democratic theory gives us good reasons to question whether this account of majority rule requires some qualification.

The discussion of unresponsive legislators, in particular, deserves further consideration. Matsusaka focuses on policy incongruence between referendum results and related roll-call votes. The analysis compares district-level results of a referendum with roll-call votes for cases where citizens and elected officials have voted on the same law in a reactive referendum initiated by citizens to challenge legislation. Matsusaka suggests that there are two possible explanations for incongruence: "either they were conscious decisions to ignore majority opinion, or they were "honest mistakes"' (45). Yet, Matsusaka misses other possible explanations.

Matsusaka argues that voters elect legislators who reflect their preferences and values but, at least on some issues, these legislators do not change their votes to match the views of their constituents (45). He assumes that legislators could know the preferences of voters in their district and so the "main reason for noncongruence appears to be that legislators generally follow their ideological predispositions, independently of district opinion" (50). On his view, a large enough gap in responsiveness provides a rationale for "making more use of direct democracy" to bring policy more closely in line with public opinion (52). ${ }^{5}$

This understanding of responsiveness has limits. Consider California's Proposition 72 on whether to approve legislation that would require certain employers to provide health insurance to their employees. Matsusaka observes that, in his dataset, this referendum had the highest legislator-constituent congruence in his dataset, yet the legislation was "counterintuitively" repealed (43). He does not note that this is an example of the referendum paradox (Nurmi 1998). Consider the table on the following page, assuming each district has 100 voters: 


\begin{tabular}{lll} 
District No. & For & Against \\
\hline District 1 & 51 percent & 49 percent \\
District 2 & 51 percent & 49 percent \\
District 3 & 51 percent & 49 percent \\
District 4 & 10 percent & 90 percent \\
District 5 & 10 percent & 90 percent \\
Total voters: & 173 & 327 \\
\hline
\end{tabular}

Despite the fact that a majority of legislators (3 of 5) voted for the legislation in accordance with the majority preference of their district, there is a much clearer popular majority against the measure (327-173 voters against). On Matsusaka's account, representatives here appear to both be responsive to majorities in their districts and nonresponsive to broader majorities. How should we resolve the apparent disagreements between legislators and citizens in these situations, particularly in cases like Proposition 72, where the result was much narrower than this stylized example, with the "No" side receiving 50.8 percent of votes.

Matsusaka seems inclined to hold that the popular vote should win out, citing James Madison: "while government officials might occasionally ignore popular opinion, 'the cool and deliberate sense of the community ought ... ultimately prevail over the views of its rulers'” $(57){ }^{6}$ However, Madison was skeptical that any single institution could reflect public opinion (Garsten 2010), so it is not clear that in every instance of the referendum paradox we ought to endorse the result of the referendum. Furthermore, representatives may give reasons to justify their decision, and over time convince their constituents that their decision better reflects their values and interests (Gutmann and Thompson 2004). Incongruence under these circumstances may not be a sign of democratic failure. Assessments of democratic quality should not assume that majority preferences - of both districts and the entire electorate - are "cool and deliberate" without consideration of the conditions under which they were formed. ${ }^{7}$

Similarly, we should think about how a thin version of responsiveness might enable popular vote processes to diminish deliberative quality among representatives. Popular initiatives can provide a way forward not to majorities but to minorities of citizens with extreme policy preferences that are unlikely to gain traction in legislatures (Dyck and Lascher: 52). Indeed, examining all popular vote processes "held at the national level in polyarchies since 1980," Altman similarly finds that citizen-initiated popular vote processes are increasingly initiated by ideologically extreme opponents of the current government, a tendency that may be driven by growing partisan polarization (139). Even if these policies are not 
approved by voters, a referendum can pressure elected representatives to talk about them. This agenda-setting function can have complicated effects, including mobilizing voters in elections, disrespecting minority groups, or crowding out discussion of other public issues (Kousser and McCubbins 2005; Parkinson 2020).

The capacity of popular vote processes to address deficits in democratic responsiveness may also vary depending on the institutional design. Hollander notes that few countries in the European Union allow for citizen-initiated popular vote processes, so their use remains primarily driven by the dominant actors in democratic systems - legislative majorities - which generally use them to "protect the party system" (266; see also Smith 1976). Rather than empowering citizens, Altman argues that "the sclerotic institutions that were the very objects that motivated the embrace of direct democracy (e.g., political parties, lobbies) have shown a notable elasticity in adjusting to the process itself" (21). While I have argued that incongruence between elected officials and citizens may be democratically justifiable, congruence in the case of top-down referendums may also be fraught if it is the result of elite manipulation.

These considerations illustrate Andrew Sabl's (2015) concern that the unfiltered adoption of majority preferences is more of a folk theory of democracy, rather than a normative account of responsiveness that democratic theorists would endorse. Lisa Disch similarly contends that "if constituencies and constituent interest form not prior to, but over the course of, the representative process, then responsiveness to those interests is hardly a reliable indicator that democratic representation is functioning well" (2012: 600). While Altman emphasizes control as a democratic principle, he situates it among three others: "freedom, equality, sovereignty" (15). Popular vote processes generally allow citizens to exercise equal voting power via secret ballots, which protect free choice. Such opportunities for collective decision-making "best embody the concept of popular sovereignty" (12), particularly when they are citizen-initiated to ensure that control over the agenda is exercised by citizens rather than elites. On this view, it is not the vote alone that matters, but the entire process. Indeed, Altman argues that representative institutions will continue to play important roles, such as preventing all decisions from being made in isolation from one another (15-17).

\section{Participation and Citizenship}

Dyck and Lascher contend that normative democratic theory has misled a significant number of empirical political scientists. According to them, 
"[p]articipatory democratic theory provides the large story that has dominated research on the spillover effects of ballot initiatives in the American states" (3). Participatory democrats paint a picture of "Engagement World," in which the initiative makes citizens more interested in politics and more informed. This account is built primarily on Benjamin Barber's Strong Democracy, which contends that citizens "are apathetic because they are powerless" $(2004,272)$ and that more opportunities for unmediated participation in political decision-making would lead citizens to be more engaged. Dyck and Lascher nicely lay out the causal mechanisms that are believed to explain how popular vote processes increase turnout (9-11). They suggest that popular vote processes are expected to improve citizens' views of their own capacities, their views of the capacities of their fellow citizens, and the effectiveness of government. Citizens with higher levels of knowledge and political efficacy are expected to be more likely to vote.

Dyck and Lascher argue that this picture of "Engagement World" is "simple, clear, and wrong" (3). A primary point of contention is that participatory democratic theory's assumptions about human psychology are questionable, such as ignoring the possibility that people may find political participation unpleasant (11-14). Moreover, their review of the existing empirical research suggests little evidence in favor of the theorized mechanisms (14-18). Dyck and Lascher instead turn to the democratic theory of Schattschneider to contend that initiatives increase turnout not by creating "better" citizens, but by creating incentives for political parties and activists to mobilize voters by expanding the scope of conflict (1-2, 154-155).

The decision to focus on participatory democratic theory is understandable, given its influence on the research agenda for several decades. However, both Hollander (42) and Altman (174) acknowledge that other prominent stands of democratic theory, such as deliberative democracy, have been more skeptical of the use of popular vote processes. Many deliberative democrats, for instance, are unlikely to be enthused by Dyck and Lascher's finding that campaigners in initiatives focus on mobilizing sympathetic voters rather than on trying to persuade others (53-54).

To some extent, participatory and deliberative democrats are talking past each other. Deliberative democrats have seen poor deliberation as a problem in actually existing referendums and initiatives, whereas Barber (2004) is particularly enthusiastic about an imagined popular vote process that looks quite different-involving multi-stage, multi-option referendums - from the ones most empirical political scientists study. We need a clearer democratic theory of popular vote processes, one that recognizes the strategic origins of many existing devices while taking seriously the 
possibility that redesigned referendums and initiatives could contribute to democracy.

\section{The Strategic Use of Popular Vote Processes}

Taken together, the books under review suggest that the adoption of popular vote processes has not generally been guided by a concern for the quality of democracy. As Hollander puts it: the evidence does not suggest the existence of a "universal, direct and democratic Zeitgeist that pushed countries towards (re-)adopting referendum provisions" (92). While it appears that popular vote processes were largely adopted because political actors saw them as strategically useful at some particular point in time, this should not foreclose the democratic potentials of these devices. Rather, it should lead us to consider the question of reform in more depth.

Citizen-initiated popular vote processes, according to Altman, "are usually introduced in times of political change and instability" (50) by strategic reformers who believe that the initiative would produce their desired policies (Bowler et al. 2002; Bridges and Kousser 2011). Previously identified examples of such crises include governments that anticipated losing power and wanted to weaken legislative institutions for their successors (Smith and Fridkin 2008). Political actors may see referendums or initiatives as a solution because of past experience with popular vote processes or the experiences of neighboring countries (Altman: 55-82; Hollander: 58-59).

Hollander similarly suggests that political upheaval in Europe played a key role in constitutional developments that led to the institutionalization of top-down popular vote processes (90-91). Rather than being driven by widespread citizen demands, the adoption of top-down referendums appear elite-driven. Hollander notes that she "found no support for the hypothesis that the larger the public demands for referendums, the more likely it is that referendums will be institutionalized and used" (277). The resulting design of popular vote processes permitted in a given jurisdiction also tends to reflect the consensus or majoritarian nature of the broader democratic system. For instance, consensus democracies are more likely to allow legislative minorities or citizens to trigger referendums in comparison to majoritarian democracies. The result, is that, rather than empowering citizens vis-à-vis their representative institutions, popular vote processes often "reinforce existing party competition dynamics" (Hollander: 273).

Overall, political crises create opportunities for policy entrepreneurs to mobilize antiparty sentiment in order to demand increased 
participation that they believe will produce their desired policies. The improvement of democracy is often given as a rationale, although it is not clear that popular vote processes are effective on this front. In the United States, Dyck and Lascher point to the Populist and Progressive movements as key players in the adoption of the initiative, seeing it as a way of combating "institutionalized corruption and the party machine system" (9; see also Bowler and Donovan 2006). However, initiative campaigns still continually "remind voters about problems that they either think have been solved or believe that legislators should address" (141). Regardless of which dataset or variables are used, the use of the popular initiative appears to reduce trust in state governments and lower evaluations of democracy (143). ${ }^{8}$

Beyond the adoption of popular vote processes, we need an account of how these institutions are changed and undone. Despite the widespread assertion that popular vote processes are a kind of Pandora's Box - that they cannot be abolished once implemented (Altman: 59) - the recent decision by the Netherlands to eliminate the citizen-initiated advisory referendum demonstrates that, while rare, this kind of institutional change is also possible.

Does the introduction and expanded use of popular vote processes count as democratization? Is the abolition of these devices a sign of democratic backsliding? The books under review suggest that the answer is probably "it depends." It is not only institutional variation that needs to be considered in our evaluations of popular vote processes, but also how these institutions are integrated into democratic systems. For example, Altman anticipates the recent "systemic" turn in democratic theory (el-Wakil and McKay 2019; Warren 2017), and contends that his book is about "democracy at large, its functioning, its institutions, and its innovations" (17). This is a step in the right direction, although empirical research would benefit from a more rigorous assessment of the democratic quality of popular vote processes, and recommendations for reform need a clearer grounding in democratic principles.

\section{Democratic Quality of Referendums}

While there is a robust literature that measures the quality of democracy within political systems or within elections (Elklit and Reynolds 2005; Martínez i Coma and van Ham 2015), until recently we have lacked clear measurements for the democratic quality of popular vote processes (Altman: 85; Hollander: 174). ${ }^{9}$ The books under review sketch out many of the trade-offs that arise between different kinds of popular vote processes 
(Altman: 213; Matsusaka: 129-137). Hollander draws upon disagreements in democratic theory in order to classify different kinds of popular vote processes (28). For instance, she suggests that different types of popular vote processes emphasize participation or representation, depending on who triggers the referendum, and aggregation or integration, depending on the extent to which they emphasize majority rule. The resulting classification is interesting because it highlights some of the interactions between popular vote processes and representative institutions. Through this lens, it is difficult to develop, conceptualize, and measure the democratic quality of popular vote processes because different types already reflect different democratic ideals.

In contrast, Altman suggests that we need to amalgamate "some elements of the three of the major streams of democratic theory: representative, direct, and deliberative democracy" (201). Such a normative theory would make it possible not only to recommend adding or removing particular kinds of popular vote processes (Altman: 187; Matsusaka: 129-137), but to assess the other important variations in popular vote processes (el-Wakil and Cheneval 2018) - signature thresholds, implementation of deliberative mini-publics, campaign regulation - that do not usually factor into typologies but that are at the center of many reform proposals.

Existing measures of democratic quality only capture part of the picture. Altman's “Direct Democracy Practice Potential” index measures the ease with which citizens can initiate popular vote processes, how difficult it is for a measure to pass, and how consequential these processes are in 200 countries (62). ${ }^{10}$ This index responds to concerns about whether these devices empower citizens, although we likely also need to consider the specific rules that govern these processes (Reidy and Suiter 2015), the quality of information (Renwick et al. 2019), and other features in order to develop evaluative standards that are sufficiently multifaceted.

\section{Conclusion}

Democratic theorists will likely find some of the books more satisfying than others. Matsusaka's book provides an accessible overview of some of the key debates around the use of popular vote processes, although its recommendations around the expansion and reform of popular vote processes appear to be based on a relatively thin conception of democratic theory. Hollander's book draws on democratic theory to inform its classification of popular vote processes and democratic systems, although contemporary democratic theorists have increasingly sought to synthesize these models. Dyck and Lascher's Initiatives without Engagement 
convincingly shows that some of the empirical predictions made by participatory democratic theorists do not appear supported by the evidence, at least in the case of initiatives in US states. Altman's Citizenship and Contemporary Direct Democracy is empirically ambitious, bringing together original datasets covering all democracies over a period of more than 100 years to bear on important questions, ${ }^{11}$ and theoretically sophisticated, including careful consideration of a wide range of democratic values. Overall, all four books under review advance the comparative study of the adoption, use, and effects of popular vote processes. Altman's book, in particular, provides a model for scholars looking to develop the normative consequences of their empirical research.

While I have focused on how democratic theory could complement empirical research, many of the current debates in democratic theory about popular vote processes remain constrained by the "core" of democratic theory (Saward 2019). I want to conclude by highlighting the ways in which empirical research also opens new doors for political theorists. For instance, increasing empirical study of popular vote processes outside of North America and Europe (Altman 2018) should be accompanied by comparative democratic theory to ensure that the systems are addressed in context. While issues of minority oppression loom large in discussion of popular vote processes, relatively little consideration has been given to the agentic capacity of disadvantaged groups to use popular vote processes to advance their representative claims. Lastly, while we now have a firm empirical understanding of the adoption and diffusion of popular vote processes, we lack an accompanying history of popular vote processes in political thought.12

\section{Acknowledgments}

I would like to thank Alice el-Wakil and Anna Krämling for comments on an earlier draft of this essay.

D Spencer McKay is Social Sciences and Humanities Research Council Postdoctoral Fellow, affiliated with New York University. E-mail: spencermckay1@ gmail.com

\section{NOTES}

1. The term "popular vote process" is increasingly recognized as the preferred umbrella term to refer to different kinds of referendum and initiative processes as it preserves institutional variation and avoids assuming that the associated devices are democratic. The term does not include the recall, as 
this is a kind of negative election rather than a vote on policy. I discuss this choice in the context of the reviewed books in the below section "Popular Vote Processes as Institutions". For background, see (Cheneval and el-Wakil 2018; el-Wakil and Cheneval 2018; Landemore 2018; el-Wakil and McKay 2019) For the roots of this usage, see also Budge (2006).

2. It is worth reinforcing that Switzerland is excluded from the analysis, despite the significance of popular vote processes to its political system (Hollander).

3. For a notable early critique of this tendency, see Uleri (1996).

4. Indirect initiatives are those in which proposals are sent to state legislatures for consideration prior to potentially appearing on the ballot.

5. Altman similarly argues that citizen-initiated popular vote processes provide citizens with a "safety valve" that can be used to demand responsiveness by vetoing legislation or introducing new proposals $(1,15,219)$. Such a safety valve is particularly valuable in situations where officeholders have few incentives for responsiveness, such as in the "inter-election spaces [that] constitute the weakest link within current democracies” (210-211).

6. Mobilized voters may not be representative of the broader population, and so polling may provide a better snapshot of public opinion, although with notable concerns about nonpreferences. Additionally, some voters may change their minds between the initial legislation and the referendum, perhaps because top-of-head preferences may be scrutinized during a campaign, which may misrepresent the degree of nonresponsiveness.

7. Beyond concerns about deliberation discussed below, legislatures do not usually worry about turnout in the same way that referendum campaigns do.

8. It is not clear that all citizen-initiated popular vote processes have similar effects. Reactive referendums, which allow citizens to challenge laws introduced by legislatures, appear to garner support from moderates in a way that may be more amenable to building trust between citizens and their representatives (Altman 2018: 137). Altman raises the possibility that it is actually distrust in elected representatives that drives the use of popular vote processes (2018: 153). While Dyck and Lascher do not address this question specifically, their discussion of reverse causality may provide reasons for thinking that it is popular vote processes that drive distrust and not the other way around (62-63). More research needs to be done on the relationship between the availability and use of popular vote processes and trust in democratic institutions.

9. A new paper by Kersting and Grömping (2021) is the most comprehensive attempt to remedy this problem.

10. Altman describes the constituent parts of the index as follows: "Regarding each type of popular vote (i.e. popular initiative), the ease of initiation is measured by: a) the existence of that direct democracy process, b) the number of signatures needed, c) time-limits for the collection of signatures, and d) the level of government (national and/or subnational). The relative ease of approval is measured by the surface of the polygon determined by: a) the participation quorum, b) the approval quorum, and c) supermajority requirements. 
The resulting score is then multiplied by: d) district majority. Consequences are measured by: a) the legal status of the decision made by citizens (binding versus consultative), and b) the frequency and degree of success with which direct popular votes have been held in the past" (62).

11. Unfortunately, some of them could not be addressed here, such as his investigation of ideological bias in popular vote processes.

12. Pierre Rosanvallon's (2000) La Démocratie Inachevée is, to my knowledge, the best existing account, although it is not available in English and focuses primarily on France with less detailed investigation of the American, German, and Swiss experiences.

\section{REFERENCES}

Altman, David. 2011. Direct Democracy Worldwide. Cambridge: Cambridge University Press.

Altman, David. 2018. Citizenship and Contemporary Direct Democracy. Cambridge: Cambridge University Press.

Barber, Benjamin. 2004. Strong Democracy: Participatory Politics for a New Age. Berkeley: University of California Press.

Bowler, Shaun, and Todd Donovan. 2006. "Direct Democracy and Political Parties in America.” Party Politics 12 (5): 649-669. doi:10.1177/1354068806066792.

Bowler, Shaun, Todd Donovan, and Jeffrey A. Karp. 2002. "When Might Institutions Change? Elite Support for Direct Democracy in Three Nations.” Political Research Quarterly 55 (4): 731-54. doi:10.1177/106591290205500401.

Bridges, Amy, and Thad Kousser. 2011. "Where Politicians Gave Power to the People: Adoption of the Citizen Initiative in the U.S. States." State Politics \& Policy Quarterly 11 (2): 167-197. https://www.jstor.org/stable/41575820.

Budge, Ian. 2006. "Direct and Representative Democracy: Are They Necessarily Opposed?” Representation 42(1): 1-12.

Cheneval, Francis, and Alice el-Wakil. 2018. "The Institutional Design of Referendums: Bottom-Up and Binding.” Swiss Political Science Review 24 (3): 294-304. doi:10.1111/spsr.12319.

Disch, Lisa. 2012. "Democratic Representation and the Constituency Paradox.” Perspectives on Politics 10 (3): 599-616. https://www.jstor.org/stable/23260181.

Dyck, Joshua, and Edward Lascher. 2019. Initiatives without Engagement: A Realistic Appraisal of Direct Democracy's Secondary Effects. Ann Arbor, MI: University of Michigan Press. http://www.press.umich.edu/9993024 (February 5, 2019).

Elklit, Jørgen, and Andrew Reynolds. 2005. "A Framework for the Systematic Study of Election Quality.” Democratization 12 (2):147-162. doi:10.1080/13510340500069204.

el-Wakil, Alice, and Francis Cheneval. 2018. "Designing Popular Vote Processes to Enhance Democratic Systems.” Swiss Political Science Review 24 (3): 348-358. doi/10.1111/spsr.12318.

el-Wakil, Alice, and Spencer McKay. 2019. "Disentangling Referendums and Direct Democracy: A Defence of the Systemic Approach to Popular Vote Processes.” Representation 55 (1): 1-18. doi:10.1080/00344893.2019.1652203. 
el-Wakil, Alice, and Spencer McKay. 2020. "Introduction to the Special Issue 'Beyond "Direct Democracy": Popular Vote Processes in Democratic Systems."” Representation 56 (4): 435-47. doi:10.1080/00344893.2020.1820370.

Fleuß, Dannica, and Gary S. Schaal. 2019. "What Are We Doing When We Are Doing Democratic Theory?” Democratic Theory 6 (2): 12-26. doi:10.3167/dt.2019.060203.

Garsten, Bryan. 2010. "Representative Government and Popular Sovereignty." In Political Representation, ed. Alexander S. Kirshner, Elisabeth Jean Wood, Ian Shapiro, and Susan C. Stokes, 90-110. Cambridge: Cambridge University Press.

Gutmann, Amy, and Dennis Thompson. 2004. Why Deliberative Democracy? Princeton, NJ: Princeton University Press.

Hollander, Saskia. 2019. The Politics of Referendum Use in European Democracies. Palgrave MacMillan.

Hug, Simon. 2009. “Some Thoughts about Referendums, Representative Democracy, and Separation of Powers.” Constitutional Political Economy 20 (3-4): 251266. doi:10.1007\%2Fs10602-008-9065-1.

Jäske, Maija, and Maija Setälä. 2019. “A Functionalist Approach to Democratic Innovations.” Representation 56 (4): 467-483. doi:10.1080/00344893.2019.1691639.

Kousser, Thad, and Mathew McCubbins. 2005. "Social Choice, Crypto-Initiatives, and Policymaking by Direct Democracy.” Southern California Law Review 78 (4): 949-984. doi:10.2139/ssrn.672664.

Landemore, Hélène. 2018. "Referendums Are Never Merely Referendums: On the Need to Make Popular Vote Processes More Deliberative.” Swiss Political Science Review 24 (3): 320-327. doi:10.1111/spsr.12314.

Martínez i Coma, Ferran, and Carolien van Ham. 2015. "Can Experts Judge Elections? Testing the Validity of Expert Judgments for Measuring Election Integrity.” European Journal of Political Research 54 (2): 305-325. doi:10.1111/1475-6765.12084.

Matsusaka, John G. 2020. Let the People Rule: How Direct Democracy Can Meet the Populist Challenge. Princeton: Princeton University Press.

Nurmi, Hannu. 1998. "Voting Paradoxes and Referenda." Social Choice and Welfare 15 (3): 333-350. doi:10.1007/s003550050109.

Parkinson, John. 2020. “The Roles of Referendums in Deliberative Systems.” Representation 56 (4): 485-500. doi:10.1080/00344893.2020.1718195.

Reidy, Theresa, and Jane Suiter. 2015. "Do Rules Matter? Categorizing the Regulation of Referendum Campaigns.” Electoral Studies 38: 159-169. doi:10.1016/j. electstud.2015.02.011.

Renwick, Alan, Michela Palese, and Jess Sargeant. 2019. “Information in Referendum Campaigns: How Can It Be Improved?” Representation 56 (4): 521-537. do $\mathrm{i}: 10.1080 / 00344893.2019 .1661872$.

Rosanvallon, Pierre. 2000. La Démocratie Inachevée: Histoire de La Souveraineté Du Peuple En France. Paris: Gallimard.

Sabl, Andrew. 2015. "The Two Cultures of Democratic Theory: Responsiveness, Democratic Quality, and the Empirical-Normative Divide." Perspectives on Politics 13 (2): 345-365. doi: 10.1017/S1537592715000079.

Saward, Michael. 2019. “Theorizing about Democracy.” Democratic Theory 6 (2): 1-11. doi:10.3167/dt.2019.060202. 
Smith, Daniel A., and Dustin Fridkin. 2008. "Delegating Direct Democracy: Interparty Legislative Competition and the Adoption of the Initiative in the American States.” American Political Science Review 102 (3): 333-350. doi:10.1017| S0003055408080258.

Smith, Gordon. 1976. “The Functional Properties of the Referendum.” European Journal of Political Research 4 (1): 1-23. doi:10.1111/j.1475-6765.1976.tb00787.x.

Uleri, Pier Vincenzo. 1996. "Introduction.” In The Referendum Experience in Europe, ed. Michael Gallagher and Pier Vincenzo Uleri, 1-19. London: Palgrave Macmillan.

Warren, Mark E. 2017. “A Problem-Based Approach to Democratic Theory.” American Political Science Review 111 (1): 39-53. doi:10.1017/S0003055416000605. 